\section{DILATATION OF THE HEART AND AORTA, WITH CURIOUS \\ DISEASED FORMATION OF THE AORTIC ARCH.}

\section{To the Editor of The LANCET.}

Srr,-Archibald Legget, aged 30, a labourer, died from disease of the heart on the 15th of June last. He suffered so much for a year previous to his death as to be nnable to follow any employment whatever.

Autopsy.-Heart very much enlarged. Its circumference behind the auricles was fourteen inches and a half. The lowest aortic valve was tucked down, in its free edge, to nearly half its natural size, by which permanent patency existed. The aorta was enlarged and about double its usual size, and all vestige of the arch was gone. It was in a contınuous line with the carotid arteries, although those vessels were not much if at all eniarged. excepting at their origin. The subclavians were not in the least enlarged. The aorta, at about half way between its origin and the giving off of the carotids, made a bend to the right, in the form of an obtuse pouch, in its right walls, of a quarter of an inch in depth. It was a mere dilatation of its coats, which were not thinner at that part. The pouch was in the direction of the diseased sigmoid valve, and from that valve being permanently contracted the force of the current of the blood would be directed against that side of the vessel, at that part, producing the dilatation. The left side of the vessel, opposite, was slightly bent towards its fellow. From the floor of the aorta, and beyond the centre of the pouch, where the current would be returning to the nearly straight line, and at about one-third from the giving off of the carotids, sprung the descending aorta, by a round aperture of much smaller dimensions than the portion of the vessel from which it originated. On quitting the ascending aorta, and instantly as it left its walls, it bulged out into a cone-like form, of a calibre that would hold a moderate sized Jargonelle pear, and very much of that shape, the apex pointing downwards. Its walls were thick, corrugated, and puckered, with two or three bands of itself standing inwards in bold relief. The aorta resumed its usual size, or was of rather a smaller size, where it was compressed by the heart.

The dilatation of the descending aorta would be produced by the regurgitation of the blood durng the diastole of the enormously enlarged heart. The liver was much enlarged upwards. I am, Sir, your obedient servant,

W. Henderson, M.D.

Corstorphine, Edinburgh, July 8, 1843.

\section{MOVEABLE KIDNEY.}

In the "Medical and Physical Journal" for 1825 (vol. ii., p. 476) mention was made of certain cases of equivocal moveable tumours in the abdomen which had been taken for diseased ovary, but which Dr. Baillie suspected were due to an abnormal state of the kidney. He had not opportunities of verifying his suspicions by postmortem examinations, but the correctness of his diagnosis has since been amply con. firmed.

In 1826, M. Aberle published in the "Salzburg Gazette," a case of a man, thirtysix years of age, who, having long suffered disturbance of the digestive organs, began to remark a moveable tumour to the right of the umbilical region, which he could with ease remove so as to press against different parts of the abdominal parietes. The tumour gradually increased, the patient fell into a state of marasmus, aud ultunately died. After death the spleen was found tuberculons; the pancreas hypertrophied: the right kidney healthy, but moveable, and capable of displacement with great faclity, its vessels baving become much lengthened, and its cellular envelope destitute of fat.

Since the above period M. Aberle has witnessed and recorded three other sim:lar cases. One occurred in a woman, sixty-six years of age, who had died of apoplexy, and on opening whom a solid mass was found on the right side in front of the psoas muscle, which turned out to be the kidney, pushing downwards the ascending and palt of the transverse colon. The second case was that of a lady, seventy-five years old, who had long perceived the presence of the tumour, which became more moveable atier a sharp attack of dysentery. She, however, suffered little or nothing from it heyond some pain after fatigung walks. The throd case occurred after menstrual disorder; but the patient suffered little material inconvenience. In THE LANCET, Jan. 21st, 1n37, (p. 587) an avalogous case is reported by ir. King. It is remarkable that in all these cases the anomaly has occurred on the right side, and mostly in women. - Schmidt's Jahrbuch, vol. xxxvii., p. 312.

Lovis found tubercles in the small intes. tines of one third of the phthisical patieuts he examined; while of one hundred patients examined by Lombard, tubercles were found in the jutestines of twenty-six ; in the mesenteric grands of nineteen; in the cervucal glands of seven; in the axillary glands and anterior mediastinum of three; in the arachnoid, spinal chord, pleura, intercostal muscles, and ovaries, of two; in the gallhladder, liver, posterior mediastinum, vertebræ, ribs, omentum, uterus, bladder, cerebrum, cerebellum, medulla oblongata, and kidneys, of one. 